Article

\title{
Calcium Phosphate Growth at Electropolished Titanium Surfaces
}

\section{EInaz Ajami ${ }^{1, *}$ and Kondo-Francois Aguey-Zinsou ${ }^{2}$}

1 School of Engineering and Materials Science, University of London, Queen Mary, London E1 4NS, UK

2 School of Chemical Engineering, The University of New South Wales, Sydney NSW 2052, Australia; E-Mail: f.aguey@unsw.edu.au

* Author to whom correspondence should be addressed; E-Mail: elnaz.ajami@utoronto.ca; Tel.: +61-293-857-970; Fax: +61-293-855-966.

Received: 7 February 2012; in revised form: 21 March 2012 / Accepted: 11 April 2012 /

Published: 25 April 2012

\begin{abstract}
This work investigated the ability of electropolished Ti surface to induce Hydroxyapatite (HA) nucleation and growth in vitro via a biomimetic method in Simulated Body Fluid (SBF). The HA induction ability of Ti surface upon electropolishing was compared to that of $\mathrm{Ti}$ substrates modified with common chemical methods including alkali, acidic and hydrogen peroxide treatments. Our results revealed the excellent ability of electropolished Ti surfaces in inducing the formation of bone-like HA at the Ti/SBF interface. The chemical composition, crystallinity and thickness of the HA coating obtained on the electropolished Ti surface was found to be comparable to that achieved on the surface of alkali treated Ti substrate, one of the most effective and popular chemical treatments. The surface characteristics of electropolished Ti contributing to HA growth were discussed thoroughly.
\end{abstract}

Keywords: surface treatment; electropolishing; titanium; hydroxyapatite; biomimetic; biomaterial

\section{Introduction}

Titanium (Ti) and its alloys are popular biomaterials for load-bearing endosseous implants, because they exhibit a combination of favorable properties such as adequate mechanical strength, sufficient 
formability, low specific weight, excellent corrosion resistance and biocompatibility $[1,2]$. In terms of bone bonding, Ti can bond to bone [3], however the osteointegration does not occur well with unmodified Ti surfaces [2] and the bio-passive properties of Ti surfaces usually hinder the healing process [4]. To overcome such difficulties, there has been a growing interest in surface coating of Ti implants with Hydroxyapatite (HA), so that great osteoconductivity of HA combines with excellent mechanical properties of Ti. Popularity of HA among other calcium phosphate phases is because of its thermodynamic stability in biological conditions [5] and its existence in bone mineral phase. To date, various physical methods of HA coating on Ti surfaces have been investigated [1,6,7], however, the only commercially accepted method is plasma spraying. Major disadvantages associated with plasma spraying, i.e., high processing temperatures and poor integration of the coating with the metallic surface [8], have drawn attentions towards development of chemical coating methods based on mimicking biomineralization process [9]. In such biomimetic methods, the HA coating is produced by immersing the surface in a solution supersaturated with respect to HA (normally SBF) at a physiological temperature and $\mathrm{pH}$, and a better $\mathrm{HA}$ integration onto metallic surface is achieved. However, kinetics of HA crystal nucleation and growth via biomimetic method might be very slow on the unmodified $\mathrm{Ti}$ surfaces. Therefore, many chemical surface treatment methods have been suggested to enhance the surface properties of $\mathrm{Ti}$ for accelerated HA nucleation, all of which aim to clarify the basic principles guiding the formation of HA from SBF on modified Ti surfaces. However, many contradictory observations are reported due to differences in the experimental conditions and thus it is difficult to draw a definitive conclusion on the mechanism of HA nucleation. Nonetheless, a general observation is that the surface charge plays a critical role in enhancing the mineralization of apatite. It has been found that at deprotonated Ti oxide layers (negatively charged), the adsorption of calcium ions and subsequent phosphate deposition would occur [10,11]. However, at positively charged Ti oxide surfaces, competitive adsorption between phosphate and chloride ions from SBF was found to hinder the growth of calcium phosphate phases [12]. For that reason, attempts have mainly focused on implanting negative ions at the surface of Ti by chemical or physical methods. Common chemical methods rely on the use of hydrogen peroxide [13], alkaline [7,14-16] or acidic solutions [17]. The titanate gel layer obtained after these treatments bears negatively charged surface groups under physiological conditions, which facilitate the precipitation of $\mathrm{Ca}^{2+}$ and further growth of apatite [15,18]. Functionalization of Ti surfaces with self-assembled monolayers (SAMs) also favors a mechanism whereby HA mineralization occurs at negatively charged surfaces only [19-24]. However, HA deposition has also been observed on positively charged SAMs, which indicates that, depending on experimental conditions (e.g., pH, temperature and ionic concentration of the SBF), various mineralization mechanisms with initial homogeneous and/or heterogeneous nucleation of apatite may occur [25].

Other methods to facilitate the deposition of HA are based on the direct implantation of ions such as $\mathrm{Na}^{+}[13,18], \mathrm{Ca}^{2+}[26,27]$ and $\mathrm{Mg}^{2+}$ [28] onto Ti surfaces. For example, sodium titanate surfaces, implanted with $\mathrm{Na}^{+}$ions, have been found to promote the nucleation and growth of HA from SBF $[18,29]$. Upon sodium titanate hydrolysis in SBF, the subsequent release of $\mathrm{NaOH}$ is believed to increase the $\mathrm{pH}$ locally, favor the deprotonation of surface hydroxyl groups and thus increase supersaturation level with respect to HA $[18,29]$ at the solution/Ti interface [28,30,31]. Although these observations may contradict other findings with respect to negatively charged Ti surfaces, they also indicate that the nucleation of apatite may only proceed by the precipitation of $\mathrm{Ca}^{2+}$ ions first. 
In this respect, the general trend observed with negatively charged Ti surfaces enhancing the mineralization of apatite has drawn our attention towards electropolished Ti surfaces. Upon electropolishing, $\mathrm{Cl}^{-}$residues are usually left at the surface of Ti within a depth of 20 to $35 \AA$ [32-34]. Such implanted ions should therefore enhance nucleation and growth of HA. To date, smooth and homogenous surfaces of electropolished Ti have only been used as well-defined starting points for subsequent surface treatments, such as anodic oxidation [33]. They have also been used as control surfaces to investigate the effect of surface roughness on cell behaviour or tissue reactions with $\mathrm{Ti}$ surfaces [35,36]. To the best of authors' knowledge, not much attention has been paid to HA nucleating ability of electropolished Ti surface and therefore, this study aims to evaluate the ability of electropolished Ti surface to induce HA nucleation and growth via biomimetic method in SBF. In order to truthfully evaluate this ability, the behaviour of electropolished Ti substrate was also compared to that of Ti surfaces modified with conventional chemical methods including alkaline [14], hydrogen peroxide/hydrochloric acid mixtures [13], and Piranha [37] pre-treatments. To this aim, a range of experimental techniques including X-ray Photoelectron Spectroscopy (XPS), Energy-dispersive X-ray (EDX), X-ray diffraction (XRD) and Fourier Transform Infrared (FTIR) spectroscopy were used to fully characterize the physical and chemical properties of the modified Ti substrates.

\section{Results and Discussion}

\subsection{Surface Properties of the Pre-Treated Ti Substrates}

The evolution of the morphology of the Ti substrates as function of pre-treatments was analyzed by SEM (Figure 1). Electropolishing resulted in a smooth surface with grain boundaries clearly observable (Figure 1, EP-Ti). However, considerable modifications of the surface morphology were observed for all the chemically treated Ti substrates. Hence, upon Piranha etching, large crevices $\left(\sim 2.5 \mu \mathrm{m}\right.$ wide) were formed at the surface of Ti (Figure 1, Pi-Ti). The use of $\mathrm{HCl}$ and $\mathrm{H}_{2} \mathrm{O}_{2}$ also resulted in the formation of a rough surface with a pore size of $\sim 1 \mu \mathrm{m}$ and crevices of $\sim 2 \mu \mathrm{m}$ long, but with additional micro-porosity (Figure 1, Cl-Ti) [13]. On the Ti surface treated with $\mathrm{NaOH}$ no crevices were observed, but a microstructure corresponding to a sodium titanate hydrogel was obtained (Figure 1, Na-Ti) [14,38,39].

The surface chemistry of the substrates after pre-treatments was characterized by XPS. All the XPS survey spectra showed peaks related to Ti, O and C (Figure 2). The Auger peaks for Ti, O and C were also observed at higher binding energies. In addition, peaks related to $\mathrm{Na} 1 \mathrm{~s}$ at 1,072 eV on Na-Ti and $\mathrm{Cl} 2 \mathrm{p}$ at $199.6 \mathrm{eV}$ on both $\mathrm{Cl}-\mathrm{Ti}$ and EP-Ti were detected. The Na1s peak was attributed to the formation of sodium titanate at the surface of $\mathrm{Ti}$ substrate pre-treated with $\mathrm{NaOH}$ [40]. Whereas, the $\mathrm{Cl} 2 \mathrm{p}$ peak was assigned to the formation of $\mathrm{TiOCl}_{\mathrm{x}}[41]$ at the surface of EP-Ti and Cl-Ti due to the adsorption of $\mathrm{Cl}^{-}$or $\mathrm{ClO}_{4}{ }^{-}$ions at the outermost surface as described previously [33,34,42]. It is noteworthy that no sulphur peaks were detected on substrates pre-treated with the Piranha solution (Pi-Ti). 
Figure 1. SEM images of EP-Ti, Pi-Ti, Cl-Ti (left) and Na-Ti (left) with scale bars of $10 \mu \mathrm{m}$. Magnified SEM images of $\mathrm{Cl}-\mathrm{Ti}$ and $\mathrm{Na}-\mathrm{Ti}$ on the right show the surface micro-porosity with scale bars of $1 \mu \mathrm{m}$.
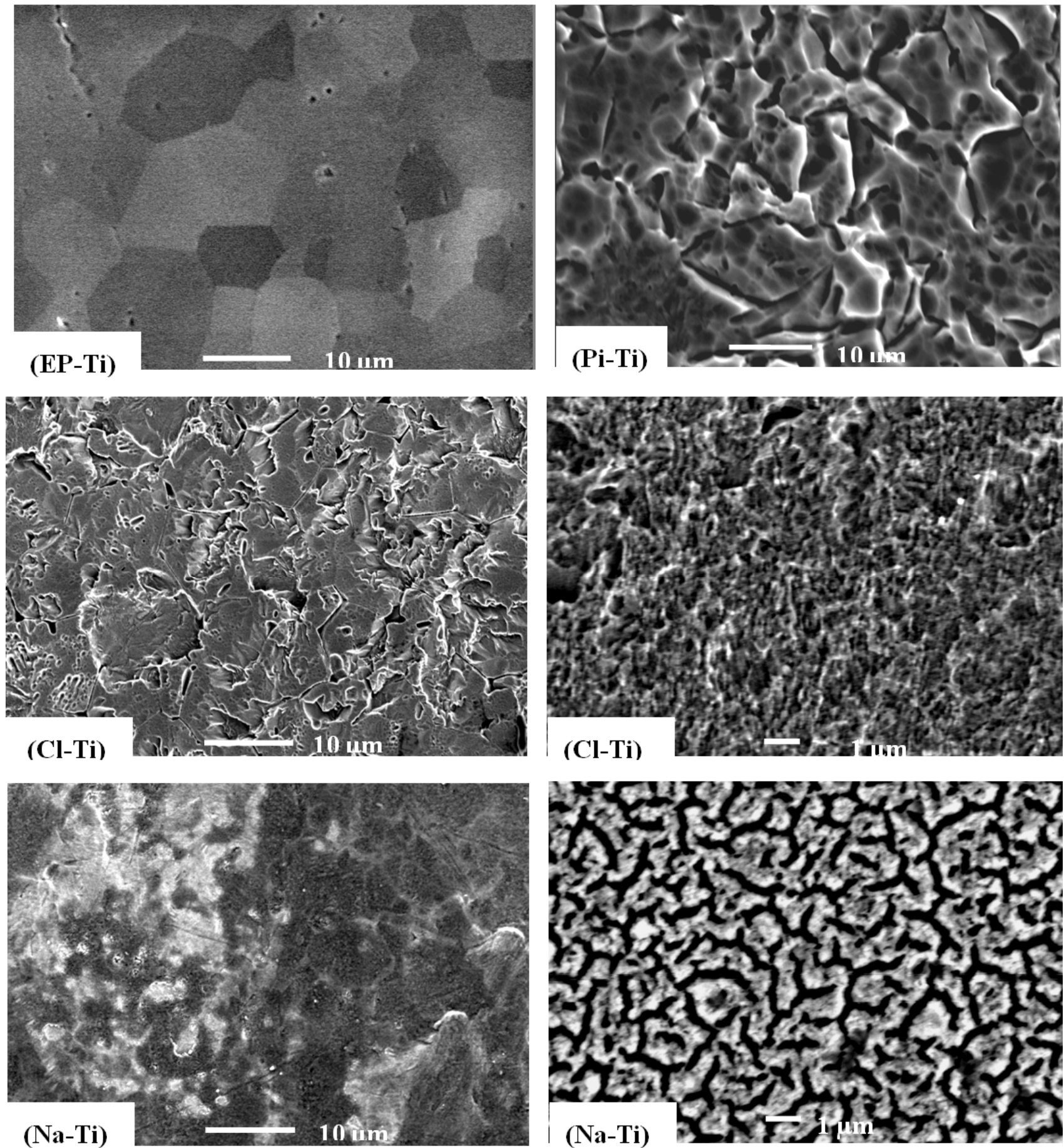
Figure 2. XPS wide-scan spectra of the electropolished and chemically treated $\mathrm{Ti}$ substrates before HA coating.

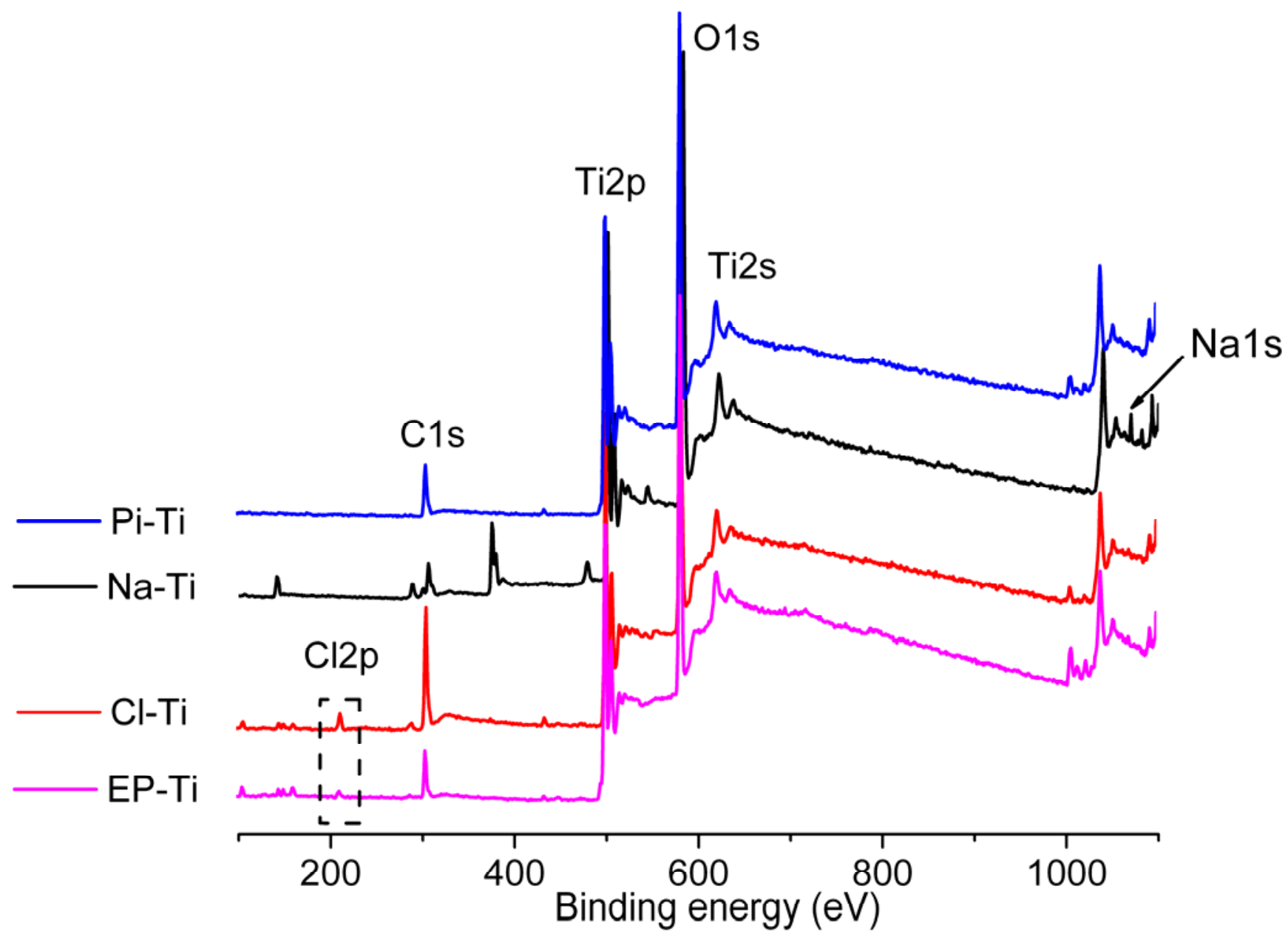

XPS narrow-scan spectra of Ti2p (Supplementary Figure S1) for all of the substrates showed two main peaks at 458.8 and $464.4 \mathrm{eV}$, corresponding to $\mathrm{TiO}_{2}$ [43-46], and a weak peak at lower binding

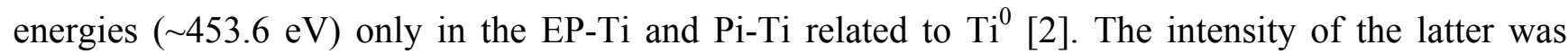
higher in EP-Ti compared to Pi-Ti, confirming a thinner oxide layer on EP-Ti, and the absence of such a peak in $\mathrm{Na}-\mathrm{Ti}$ and $\mathrm{Cl}-\mathrm{Ti}$ indicated that the thickness of the Ti oxide layer has increased beyond the penetration depth of the photoelectrons $(>7 \mathrm{~nm})$. Further characterization of the substrates in $\mathrm{C} 1 \mathrm{~s}$ region by XPS (Supplementary Figure S2) also revealed a significant level of carbon contamination due to $\mathrm{CO}_{2}$ and organic contaminants on all substrates, except on Pi-Ti. Furthermore, the XPS narrow-scan spectra in the O1s region (Supplementary Figure S3) revealed several peaks at 529, 530 and $531 \mathrm{eV}$, ascribed to the oxygen in bulk $\mathrm{TiO}_{2}(\mathrm{Ti}-\mathrm{O})$ [31,47,48], surface acidic $\left(\mathrm{OH}_{\mathrm{a}}\right)$ and basic $\left(\mathrm{OH}_{\mathrm{b}}\right)$ hydroxyl groups, respectively $[31,43,49]$. The $\mathrm{OH}_{\mathrm{a}}$ and $\mathrm{OH}_{\mathrm{b}}$ correspond to doubly and singly coordinated hydroxyls, respectively [50], and the density of these hydroxyl groups was found to decrease in the following order: Na-Ti $>\mathrm{Pi}-\mathrm{Ti} \sim \mathrm{Cl}-\mathrm{Ti}>\mathrm{EP}-\mathrm{Ti}$ (Figure 3 ). This is in agreement with previously reported data showing the highest density of hydroxyl groups on Ti substrates pre-treated with $\mathrm{NaOH}$ [51]. It should also be highlighted that EP-Ti and Pi-Ti surfaces showed $\mathrm{OH}_{\mathrm{a}}$ only, while on $\mathrm{Cl}-\mathrm{Ti}$ and $\mathrm{Na}-\mathrm{Ti}$, only $\mathrm{OH}_{\mathrm{b}}$ were found (Figure 3). 
Figure 3. Relative concentration of hydroxyl groups $\left(\mathrm{OH}_{\mathrm{a}}\right.$ and $\left.\mathrm{OH}_{\mathrm{b}}\right)$ and $\mathrm{Na}$ or $\mathrm{Cl}$ at the surface of the electropolished and chemically treated Ti substrates before HA coating. These concentrations were determined from the XPS results by taking the ratio of the peak area corresponding to a specific surface entity to that of the titanium peak.

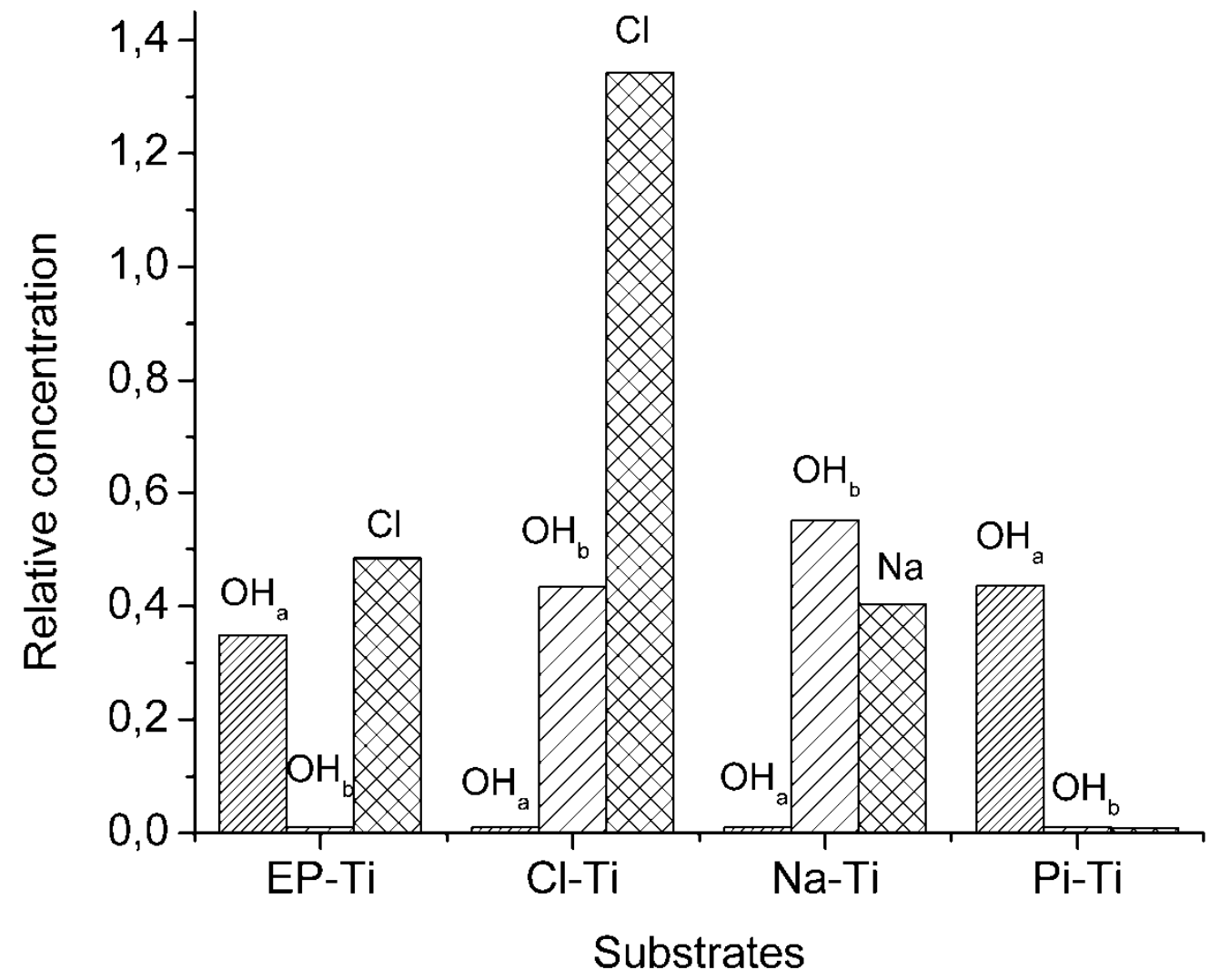

\subsection{Ti Substrates upon CaP Coating}

\subsubsection{Physical Properties of the CaP Coating}

The pre-treated substrates were immersed in 1.5 SBF and the formation of a $\mathrm{CaP}$ coating was characterized after 14 days of immersion. Except for Pi-Ti, relatively dense $\mathrm{CaP}$ coatings were found by SEM at the surface of all pre-treated substrates (Figure 4). The CaP films comprised globular structures (1 to $0.5 \mu \mathrm{m}$ ) consisting of dense plate-like crystals (Supplementary Figure S4) as a result of a three-dimensional growth process $[13,52,53]$. These globular structures are typical to biomimetic methods [38,54-62] and are observed in the bone cement line matrix interlocking with the surface of the modified titanium oxide at the bone-implant interface [63]. On the surface of Pi-Ti, only small particles of $\mathrm{CaP}$ ( $\sim 50 \mathrm{~nm}$ in diameter) were found and large globular structures of $\mathrm{CaP}$ could only be observed after 1 month of immersion (Supplementary Figure S5). Accordingly, it can be speculated that the surface of Pi-Ti induces $\mathrm{CaP}$ with slower growth kinetics. Such a slow kinetics on Pi-Ti is neither attributed to the reduced thickness of oxide layer on this surface nor to the nature of surface hydroxyl groups. The reason is that when Pi-Ti was compared to EP-Ti, the XPS Ti2p spectra (Supplementary Figure S1) proved a thicker oxide layer on Pi-Ti compared to EP-Ti, and as shown in Figure 3, both had acidic hydroxyl groups. Therefore, it is believed that lack of charged groups on the surface of Pi-Ti is the reason for its slower kinetics in inducing $\mathrm{CaP}$ growth as compared to other surfaces. 
Figure 4. SEM images of EP-Ti, Cl-Ti, Na-Ti and Pi-Ti after 14 days immersion in 1.5 SBF. Images on the right are magnified.

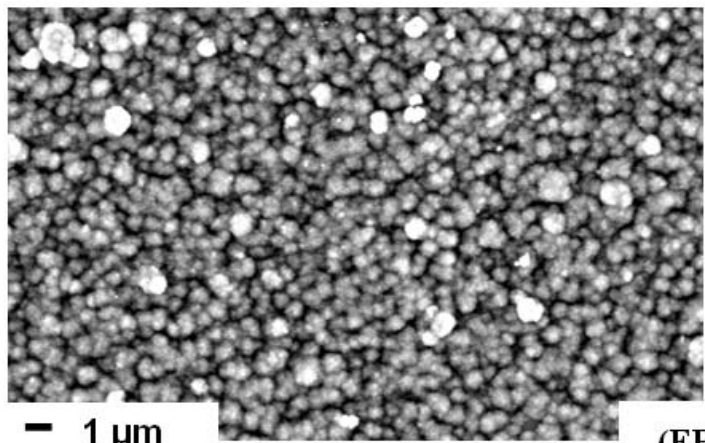

(EP-Ti)
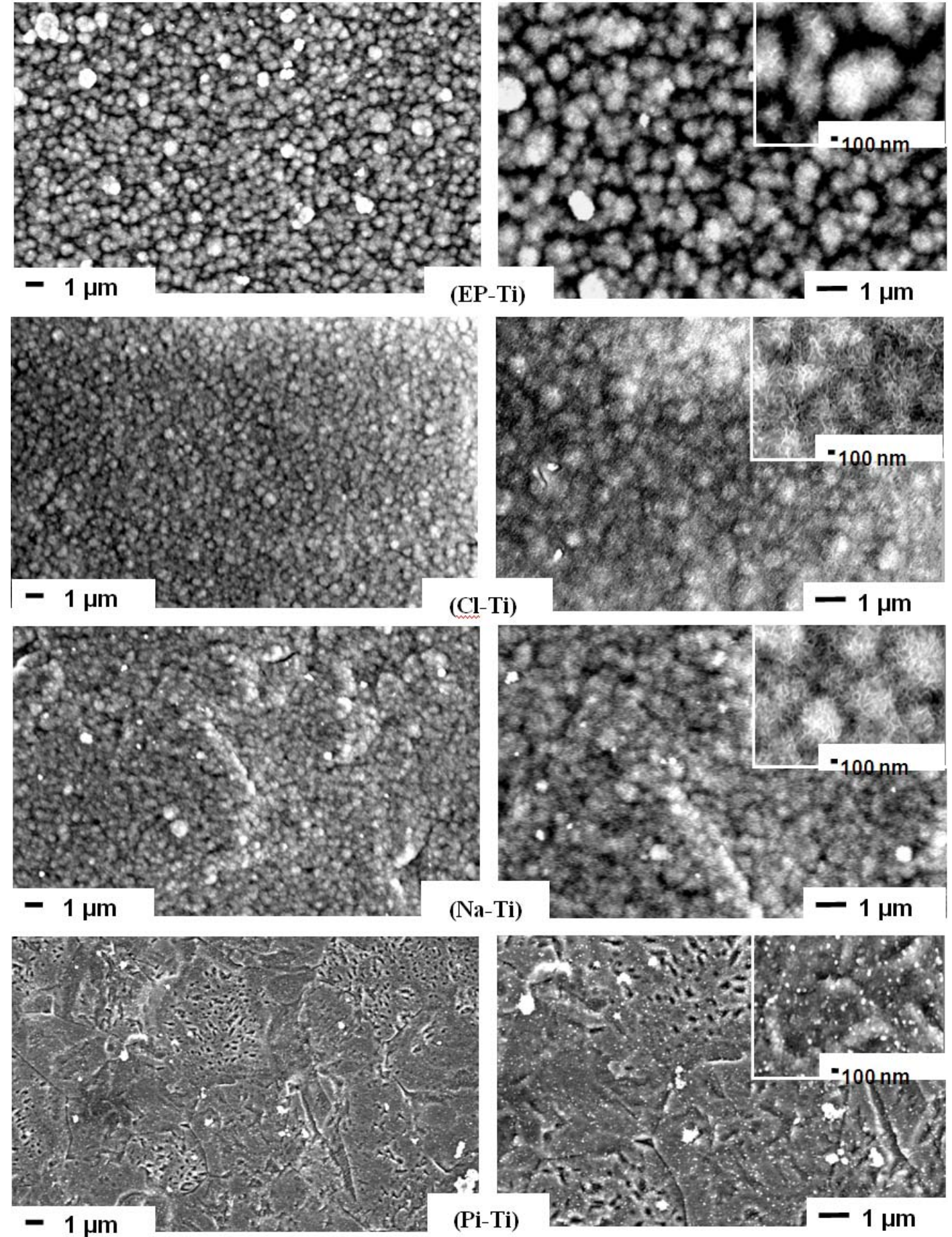

Comparing the coating on $\mathrm{Cl}-\mathrm{Ti}$ and $\mathrm{EP}-\mathrm{Ti}$, it is observed that the coating on EP-Ti is less dense than that on Cl-Ti and the underlying Ti substrate is exposed in between globular structures on EP-Ti (as indicated by arrows on the magnified inset image of EP-Ti in Figure 4). This could be explained by lower density of surface $\mathrm{OH}$ on EP-Ti compared to Cl-Ti as confirmed by XPS spectra in O1s region. Moreover, a sharper $\mathrm{Cl} 2 \mathrm{p}$ that is observed on XPS survey spectrum of Cl-Ti compared to EP-Ti shows that there are more $\mathrm{Cl}^{-}$ions contributing to the mineralization process, thus resulting in a denser coating on Cl-Ti compared to EP-Ti. 
Further characterization of the film thickness revealed that different growth regimes occur at various Ti substrates, with $\mathrm{Cl}-\mathrm{Ti}$ and EP-Ti showing the thickest film $(\sim 9.5 \mu \mathrm{m})$ after 1 month of immersion in 1.5 SBF (Figure 5). It is noteworthy that globular films have formed on all surfaces regardless of the initial surface roughness. This suggests that heterogeneous nucleation of $\mathrm{CaP}$ on $\mathrm{Ti}$ had happened immediately after immersion in 1.5 SBF and did not depend on the surface topography in agreement with previous reports [57]. However, this statement is only valid for in vitro surface-induced mineralization of $\mathrm{CaP}$ on $\mathrm{Ti}$ surfaces and it is not applicable to bone bonding onto $\mathrm{Ti}$ implant surfaces. It is very well understood that implant surfaces with complex microtopography, and not the smooth surfaces, render surfaces bone bonding [64]. In terms of in vitro surface-induced mineralization, it can be speculated that the surface topography would only influence the mechanical stability of final $\mathrm{CaP}$ film and not the initial surface-induced formation of $\mathrm{CaP}$ nuclei. This is because a more adherent $\mathrm{CaP}$ coating will be formed on rough surfaces due to increased interfacial adhesion strength between the coating and Ti surface $[57,65,66]$.

Figure 5. Evolution of the CaP film thickness on all substrates after immersion in $1.5 \mathrm{SBF}$ for 14 days and 1 month. Film thickness was measured on three different locations with cross-sectional SEM imaging. The dashed lines are guides to the eye.

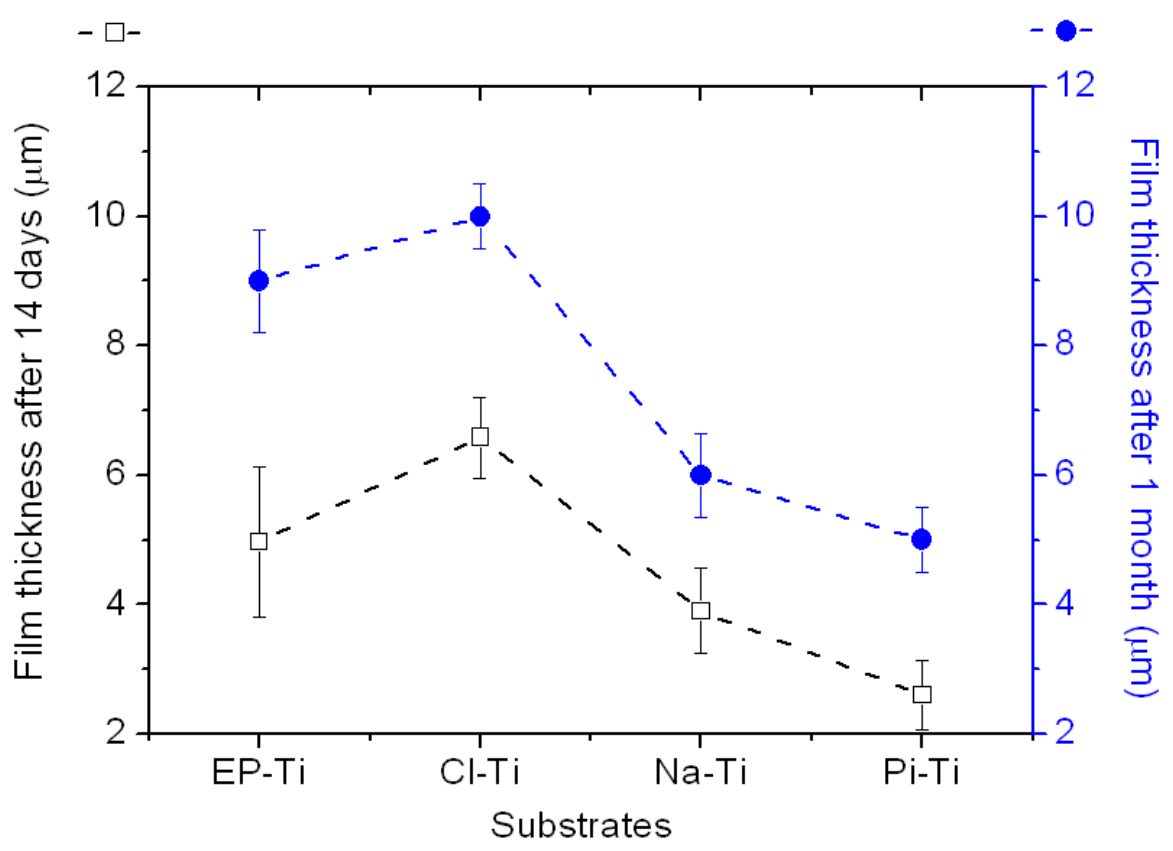

The crystallinity of the films was investigated by XRD after immersion in $1.5 \mathrm{SBF}$ for 14 days (Figure 6a). All substrates showed peaks at $2 \theta=35,38.2,40.1$ and $52.7^{\circ}$ related to the (100), (002), (101) and (102) planes of $\mathrm{Ti}$, respectively [13,18,28,55,67,68]. Once more, except for Pi-Ti, all substrates showed peaks characteristic of a carbonated HA, i.e., at $2 \theta=25.9$ and $31.8^{\circ}$. The former peak corresponds to the overlapping of the (201) and (002) planes of carbonated HA, while the latter is related to the overlapping of the (211), (112) and (300) reflections [28,55,67,69-72]. The additional peak at $2 \theta=35.5-36^{\circ}$ only appearing on the XRD patterns of the Na-Ti and Pi-Ti was attributed to the superposition of the carbonated HA or tricalcium phosphate peak. The broadness of the HA peaks also indicates very small crystal sizes and/or the orientation of crystals at different directions. The absence of these reflexes (and the low intensity of the peaks) is probably due to the thinness of the $\mathrm{CaP}$ 
film [19]. Moreover, the intensity of the peak at $2 \theta=25.9^{\circ}$ is equal to that of $2 \theta=31.8^{\circ}$ in the patterns, while it should normally be less than a quarter for the carbonated HA. This could be due to the reflection of other crystalline phases, such as crystalline dicalcium phosphate with an XRD peak at $2 \theta=23.2^{\circ}$ corresponding to (040) plane [73] and tricalcium phosphate with an XRD peak at $2 \theta=25.7^{\circ}$ corresponding to the $(1010)$ plane $[74,75]$. Both of these peaks may superimpose on the carbonated HA peak at $2 \theta=25.9^{\circ}$ resulting in a higher intensity peak.

Figure 6. XRD patterns of the $\mathrm{CaP}$ film formed on the different substrates after (a) 14 days and (b) 1 month immersion in $1.5 \mathrm{SBF}$.

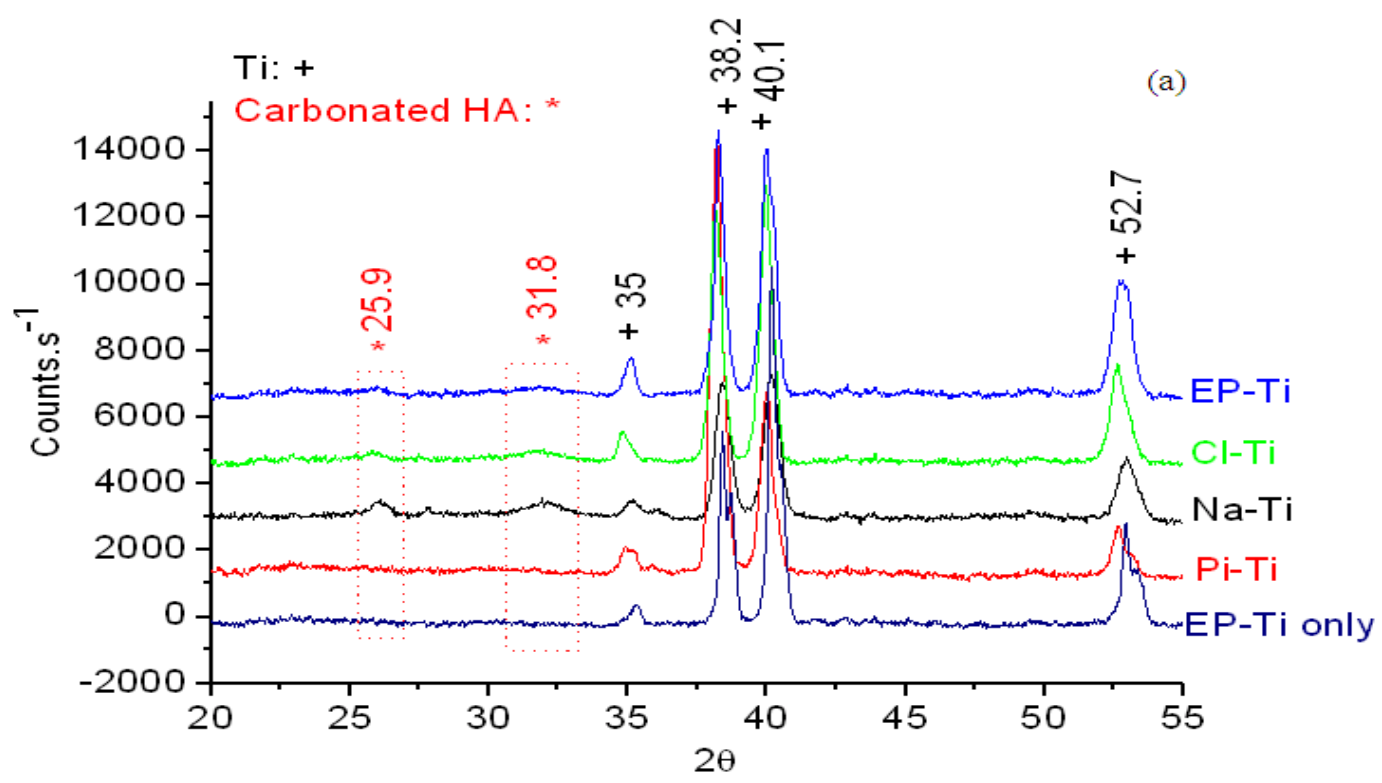

(a)

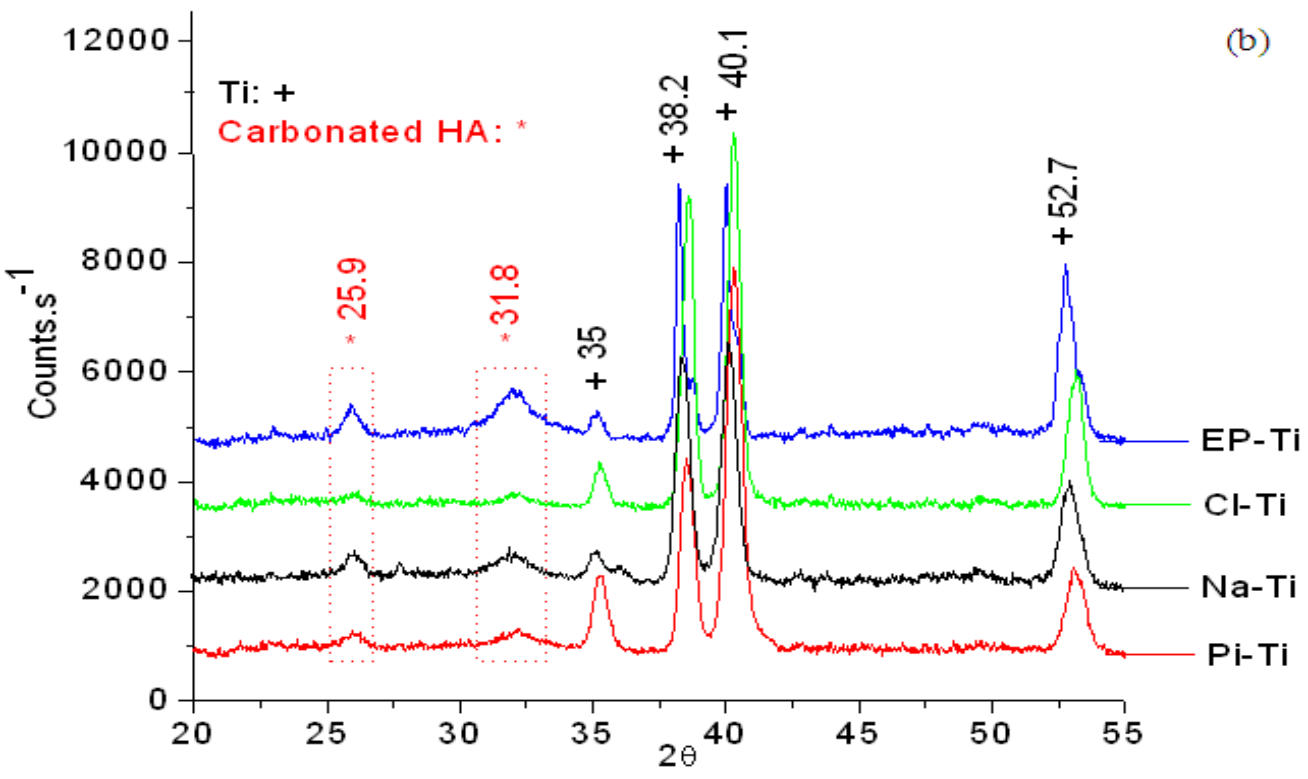

(b)

After 1 month of immersion in $1.5 \mathrm{SBF}$, the intensity of both HA peaks at 25.9 and $31.8^{\circ}$ was found to increase considerably on the EP-Ti and Pi-Ti, which confirms the formation of a thicker HA film and/or better crystallinity of the HA phase (Figure 6b). Intensity of the peaks related to HA on other 
substrates did not show much change. Further determination of the HA crystal size using the Scherrer formula [76] revealed similar crystallite sizes on all substrates expect for EP-Ti (Table 1), where HA crystallite size was found to double from 3.5 after 14 days to $6.4 \mathrm{~nm}$ after 30 days of immersion in 1.5 SBF. While the formation of a very thin film on the Pi-Ti compared to other substrates confirms fast kinetics of $\mathrm{CaP}$ film growth on the charged Ti surfaces, the formation of thickest film on the Cl-Ti proves enhanced $\mathrm{CaP}$ film growth on negatively charged surfaces in agreement with previous observations [23].

Table 1. Crystal size of HA formed at the surface of the substrates after 14 days and 1 month in $1.5 \mathrm{SBF}$.

\begin{tabular}{lcccc}
\hline HA crystallite size $( \pm \mathbf{1 . 0} \mathbf{~ n m})$ & $\mathbf{N a - T i}$ & $\mathbf{E P}-\mathbf{T i}$ & $\mathbf{P i}-\mathbf{T i}$ & $\mathbf{C l}-\mathbf{T i}$ \\
\hline after 14 days & 5.5 & 3.5 & - & 4.4 \\
after 30 days & 6.0 & 6.4 & 5.2 & 5.2 \\
\hline
\end{tabular}

\subsubsection{Chemical Composition of the Coating}

Upon EDX analysis, sharp peaks related to $\mathrm{Ca}$ and $\mathrm{P}$ were observed confirming the formation of $\mathrm{CaP}$ phases on all surfaces. Depending on the thickness of the film, peaks of different intensities related to Ti were also observed (Figure 7a). Furthermore, additional peaks corresponding to $\mathrm{C}$ and $\mathrm{Mg}$ were detected. The $\mathrm{C}$ peak was either due to the surface carbon contamination or carbonate ions in the lattice structure of CaP crystals. Similarly, it is believed that $\mathrm{Mg}^{2+}$ ions had partially substituted $\mathrm{Ca}^{2+}$ ions in the CaP lattice structure. Presence of similar traces of $\mathrm{Mg}^{2+}$ in the EDX and XPS spectra of the $\mathrm{CaP}$ film formed at alkali treated Ti surfaces also supports such a hypothesis [40,77].

Further analysis of the EDX results after 14 days of immersion in $1.5 \mathrm{SBF}$ showed that the $\mathrm{Ca} / \mathrm{P}$ ratio on $\mathrm{Pi}-\mathrm{Ti}$ is much lower than that of synthetic $\mathrm{HA}($ i.e., $~ 1.67)$ and is related to $\mathrm{Ca} / \mathrm{P}$ of dicalcium phosphate (Figure $7 \mathrm{~b}$ ). This small $\mathrm{Ca} / \mathrm{P}$ ratio could be either due to the low film thickness along with the low detection limit of the instrument, or an inadequate surface chemistry of Pi-Ti in enabling $\mathrm{Ca}^{2+}$ adsorption. However, on Na-Ti, EP-Ti and Cl-Ti, a Ca/P ratio of 1.50 was found and could be related to a Ca-deficient HA phase.

After 30 days of immersion in $1.5 \mathrm{SBF}$, the $\mathrm{Ca} / \mathrm{P}$ ratio was found to be close to that of synthetic $\mathrm{HA}$, i.e., 1.67 (Figure $7 \mathrm{~b}$ ). The $\mathrm{Ca} / \mathrm{P}$ ratio on all substrates was mainly around 1.55 , which corresponds to a Ca-deficient HA. This could be due to a partial substitution of $\mathrm{Ca}^{2+}$ by $\mathrm{Mg}^{2+}$ ions or substitution of $\mathrm{PO}_{4}{ }^{3-}$ by $\mathrm{CO}_{3}{ }^{2-}$ in the crystal lattice structure, as previously discussed. Furthermore, it can be concluded that once the initial growth regime has been completed and an equilibrium state has been achieved, the $\mathrm{Ca} / \mathrm{P}$ ratio is relatively the same on all substrates regardless of the early stages of the nucleation process. This would indicate similar growth mechanisms on all substrates after the initial nucleation and growth of the apatite.

With respect to the deposition mechanism of $\mathrm{CaP}$, the behaviour of the Na-Ti substrate in SBF has been explained by Kim et al. [15,51,78]. According to their results, the release of $\mathrm{Na}^{+}$ions from the substrate induces a $\mathrm{pH}$ increase at the substrate/SBF interface, which leads to the deprotonation of $\mathrm{OH}_{\mathrm{b}}$ groups at the Ti surface. Therefore, the adsorption of $\mathrm{Ca}^{2+}$ ions, which are initiators of the nucleation and growth of apatite, is enhanced. However, in the case of EP-Ti and Cl-Ti, the nucleation and growth 
mechanism of apatite may significantly differ, as the additional $\mathrm{Cl}^{-}$at EP-Ti and Cl-Ti may tend to stay on the surface due to the high concentration of $\mathrm{Cl}^{-}$ions in $1.5 \mathrm{SBF}$. These adsorbed $\mathrm{Cl}^{-}$may facilitate the electrostatic adsorption of $\mathrm{Ca}^{2+}$ and thus trigger the heterogeneous precipitation of a $\mathrm{CaP}$ phase. This phenomenon could also be enhanced by the deprotonation of $\mathrm{OH}_{\mathrm{a}}$ at the surface of EP-Ti, since a $\mathrm{pKa} \sim 2.9$ would be expected for the $\mathrm{OH}_{\mathrm{a}}$ populating the surface of EP-Ti [79]. However, the role of $\mathrm{OH}_{\mathrm{a}}$ in comparison to that of $\mathrm{Cl}^{-}$should be minimized, since the initial deposition of CaP phases at the Pi-Ti surface comprising only $\mathrm{OH}_{\mathrm{a}}$ surface groups is slow (Figures 3 and 5). The implantation of $\mathrm{Cl}^{-}$ions at the surface of EP-Ti would therefore explain the good CaP induction ability observed after electropolishing in comparison to conventional chemical treatments.

Other ions in SBF, in particular $\mathrm{Mg}^{2+}$ and $\mathrm{CO}_{3}{ }^{2-}$, have also influenced the nucleation and growth of $\mathrm{CaP}$, its composition and possibly its kinetics of growth, as evidenced by EDX and XRD analysis. In fact, $\mathrm{Mg}^{2+}$ and $\mathrm{CO}_{3}{ }^{2-}$ ions can compete for adsorption at the surface of $\mathrm{Ti}$ and form complexes preventing further $\mathrm{CaP}$ precipitation, as highlighted in Figure 8 (mechanisms 1, 2 and 3) [80,81]. For example, traces of $\mathrm{Mg}^{2+}$ ions have been shown to reduce the overall rate of $\mathrm{CaP}$ crystallization and delay the transformation of amorphous $\mathrm{CaP}$ to apatite phases [82]. Furthermore, the formation of magnesium phosphates in solution would reduce the amount of phosphate ions available to form $\mathrm{CaP}$ phases [80]. As a consequence, high concentrations of $\mathrm{Mg}^{2+}$ ions at the substrate/solution interface would favor the heterogeneous nucleation of poorly crystallized $\mathrm{CaP}$ phases and hinder the growth of HA crystals. This inhibitory effect of $\mathrm{Mg}^{2+}$ and $\mathrm{CO}_{3}{ }^{2-}$ ions on the growth of HA could explain the small crystal size of HA $(\sim 4-6 \mathrm{~nm})$ obtained from the XRD patterns in this work. It could also lead to strong binding of HA to the substrate [81].

Figure 7. (a) Typical EDS spectra obtained on all substrates after 14 days immersion in $1.5 \mathrm{SBF}$; (b) $\mathrm{Ca} / \mathrm{P}$ ratio of the $\mathrm{CaP}$ film as determined by EDS analysis on the substrates after 14 days and 1 month immersion in 1.5 SBF.

(a)

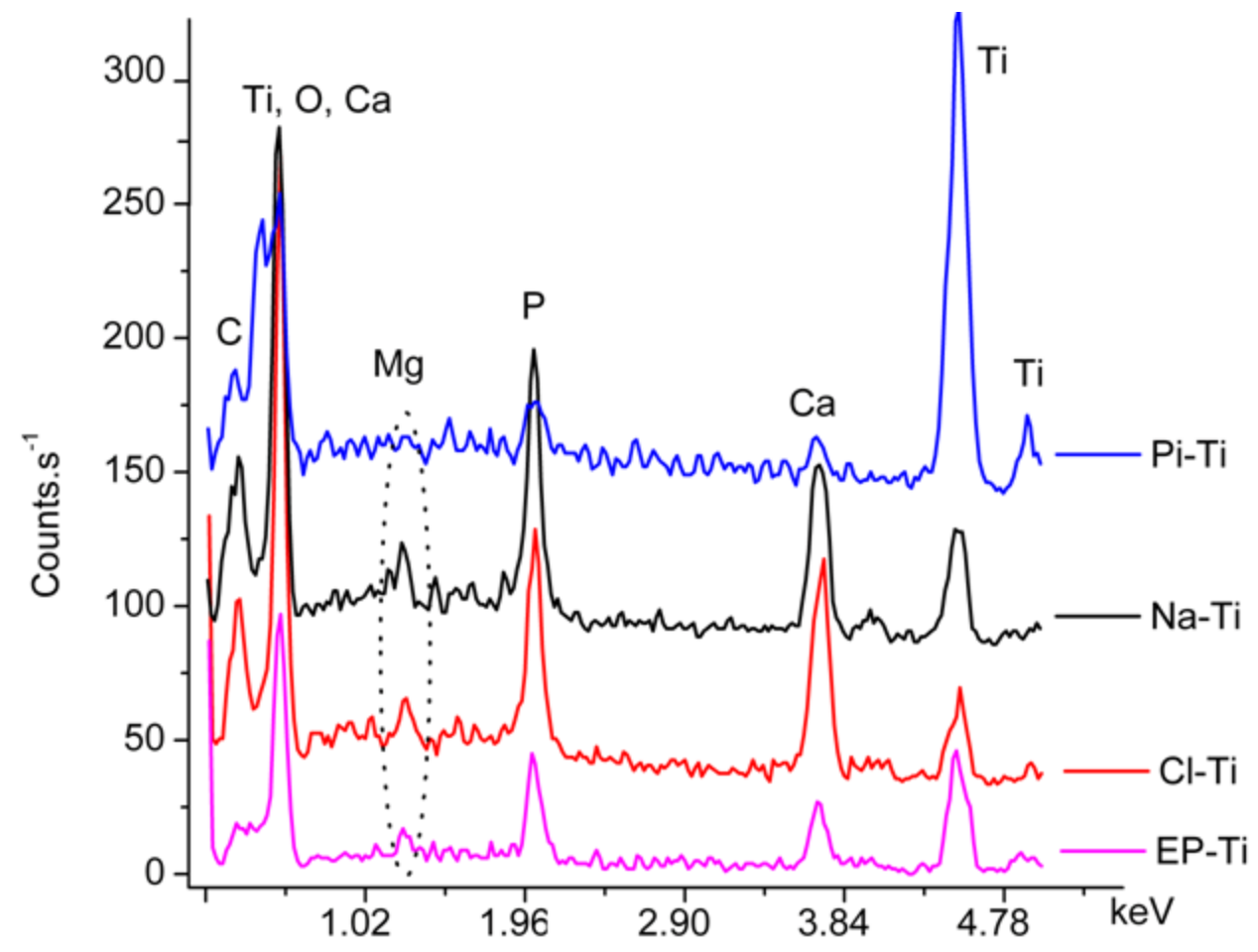


Figure 7. Cont.

(b)

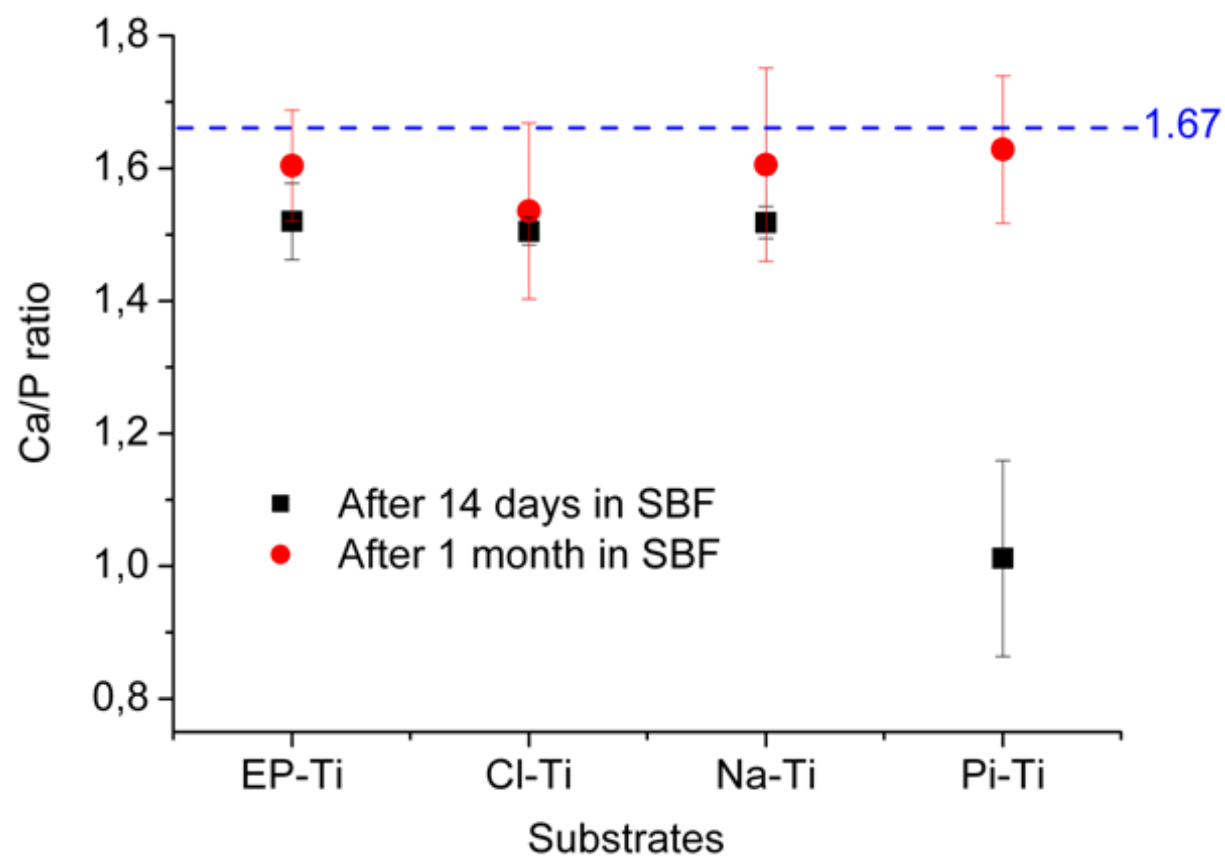

Figure 8. Proposed mechanism of $\mathrm{HA}$ nucleation in the presence of $\mathrm{Mg}^{2+}$ and $\mathrm{CO}_{3}{ }^{2-}$ ions at the Ti/SBF interface. (1) $\mathrm{Mg}^{2+}$ substitutes $\mathrm{Ca}^{2+}$ in the lattice structure or adsorbs directly on the surface; (2) $\mathrm{Mg}^{2+}$ forms magnesium phosphate and inhibits further adsorption of $\mathrm{Ca}^{2+} ;(3) \mathrm{CO}_{3}{ }^{2-}$ substitutes $\mathrm{PO}_{4}{ }^{3-}$; (4) Protonated $\mathrm{PO}_{4}{ }^{3-}$ ions after adsorption at calcium sites.

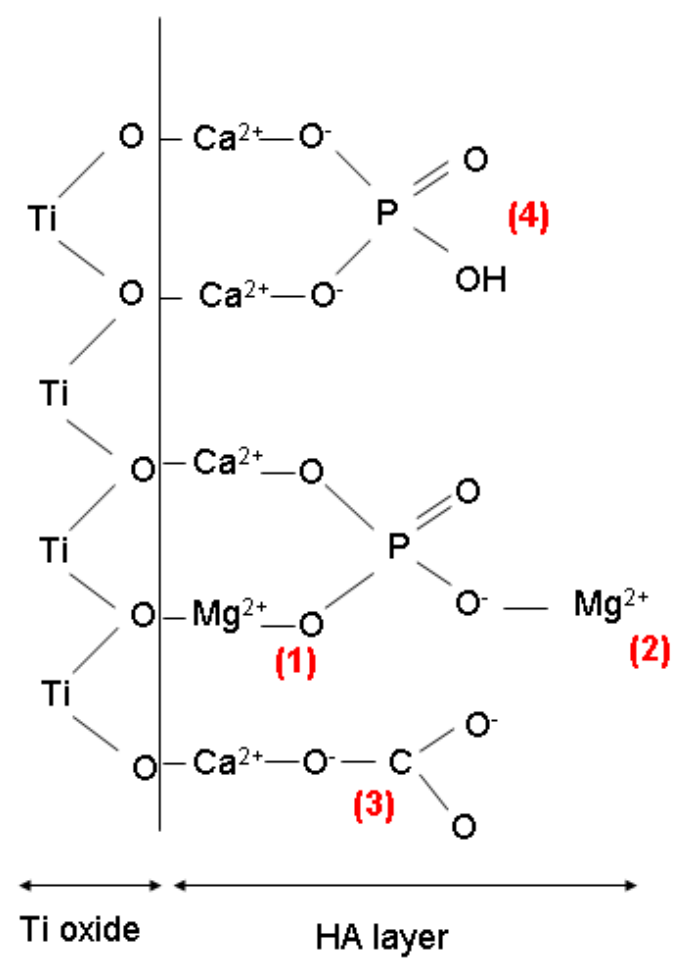<smiles>O=P([O-])([O-])[O-]</smiles>

$\mathrm{Ca}^{2+}$ $\mathrm{Mg}^{2+}$<smiles>[O-]C(O)O</smiles>

(2)

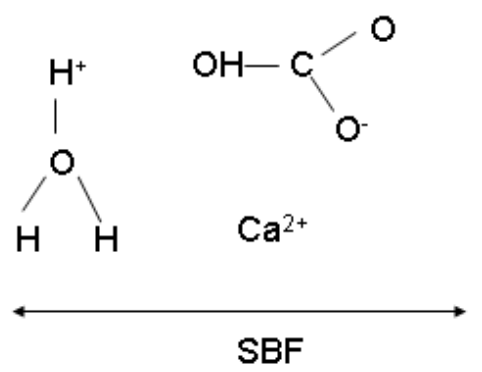

In order to determine the chemical formula of the carbonated HA formed on the substrates, further characterizations were carried out by FTIR (Figure 9 and Table 2). The obtained spectra, and the symmetric and asymmetric vibrations at 1,015-1,120 and $920 \mathrm{~cm}^{-1}$ confirmed the apatitic nature of the 
CaP films formed on all substrates. Furthermore, the vibration observed at $872 \mathrm{~cm}^{-1}$, characteristic of a B-type apatite (i.e., substitution of $\mathrm{PO}_{4}{ }^{3-}$ by $\mathrm{CO}_{3}{ }^{2-}$ ions) $[83,84]$, revealed that the apatite obtained on all substrates was partially of type-B. In fact, the frequency observed for C-O asymmetric stretching at $1,415-1,490 \mathrm{~cm}^{-1}$ is too high to correspond to a B-type apatite and is more similar to those usually observed for A-type apatite (i.e., substitution of $\mathrm{OH}^{-}$by $\mathrm{CO}_{3}{ }^{2-}$ ions) [85]. The absence of the apatite $\mathrm{OH}$ stretching peaks at $630 \mathrm{~cm}^{-1}$ also partly confirmed the substitution of A-sites by the carbonate ions [70,86-88]. However, the characteristic IR peak for the A-type apatite, i.e., at 1,545 $\mathrm{cm}^{-1}$ [89], was not observed. Therefore, an AB-type apatite had most likely formed on all the Ti substrates in agreement with previous investigations showing the formation of an AB-type apatite at neutral $\mathrm{pH}$ (7.4 for the 1.5 SBF used in the present study) $[83,85]$.

Figure 9. FTIR spectra of the substrates after 14 days immersion in 1.5 SBF. The possible shifts in the peaks between $1,015-1,120 \mathrm{~cm}^{-1}$ compared to those of stoichiometric HA are due to the presence of $\mathrm{CO}_{3}{ }^{2-}, \mathrm{HPO}_{4}{ }^{2-}$ and crystal imperfections.

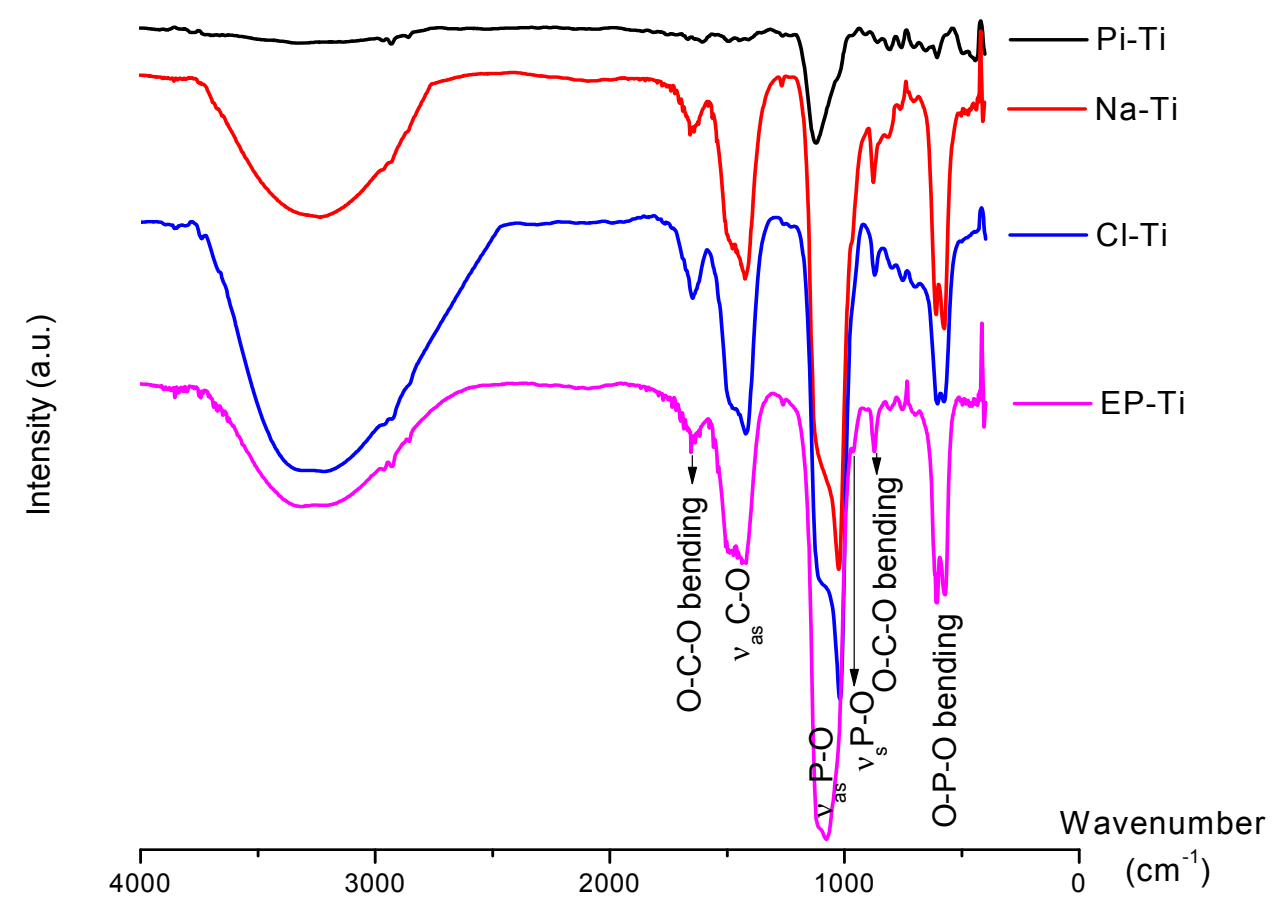

Table 2. Assignments of FTIR peaks for $\mathrm{PO}_{4}{ }^{3-}$ and $\mathrm{CO}_{3}{ }^{2-}$ vibrations on the spectra obtained and display on Figure 10.

\begin{tabular}{cc}
\hline FTIR peaks related to $\mathbf{P O}_{4}{ }^{\mathbf{3}^{-}}$ & Wavenumber $\left(\mathbf{c m}^{-\mathbf{1}}\right)$ \\
\hline$v_{4}:$ O-P-O bending & Doublet peaks at 571 and 604 \\
$v_{1}:$ P-O symmetric stretching & 960 \\
$v_{3}:$ P-O asymmetric stretching & doublet peaks between $1,015-1,120$ \\
FTIR peaks related to $\mathbf{C O}_{3}{ }^{2-}$ & Wavenumber $\left(\mathbf{c m}^{-\mathbf{1}}\right)$ \\
$v_{2}:$ O-C-O out-of-plane bending & 872 \\
$v_{3}:$ C-O asymmetric stretching & doublet peaks between $1,415-1,490$ \\
$v_{3}:$ O-C-O bending & Between $1,640-1,650$ \\
\hline
\end{tabular}


Based on these results, a chemical formula for the obtained HA film is suggested considering the fact that trivalent anionic phosphate sites can only be occupied by bivalent hydrogen phosphates or carbonate anions, and monovalent hydroxyl sites can only be substituted by carbonate ions. Furthermore, taking into account that calcium sites can be occupied by other cations and can accept a maximum of two vacant sites [90], the AB-type apatite formed may have the following formula: $\mathrm{Ca}_{10-\mathrm{x}-\mathrm{y}} \mathrm{Mg}_{\mathrm{y}}\left(\mathrm{HPO}_{4}\right)_{\mathrm{x}-\mathrm{z}}\left(\mathrm{CO}_{3}\right)_{\mathrm{z}}\left(\mathrm{PO}_{4}\right)_{6-\mathrm{x}}(\mathrm{OH})_{2-\mathrm{x}-\mathrm{w}}\left(\mathrm{CO}_{3}\right)_{\mathrm{w} / 2}, 0 \leq \mathrm{x}, \mathrm{y}, \mathrm{z}, \mathrm{w} \leq 1$.

\section{Experimental Section}

All chemicals including methanol (AR grade), perchloric acid (ACS grade, $\geq 69 \%$ ), 1-butanol (ACS grade, $\geq 99.5 \%$ ), hydrogen peroxide $30 \mathrm{wt} \%$ in water (ACS reagent), hydrochloric acid (GPR grade, $38 \%$ ), sulphuric acid (AR grade, $>97.5 \%$ ), ethanol (GPR grade), acetone (GPR grade) were purchased from Sigma and used as received. All chemicals for SBF preparation (listed in Table 3) were also purchased from Sigma (ACS reagent grade).

Table 3. Composition of 1.5 SBF listed in sequence of dissolution.

\begin{tabular}{llc}
\hline$\#$ & Chemicals & Amount (g) for 1.5 SBF in 1L of water \\
\hline 1 & $\mathrm{NaCl}$ & 10.806 \\
2 & $\mathrm{NaHCO}_{3}$ & 1.472 \\
3 & $\mathrm{Na}_{2} \mathrm{CO}_{3}$ & 4.072 \\
4 & $\mathrm{KCl}$ & 0.45 \\
5 & $\mathrm{~K}_{2} \mathrm{HPO}_{4} \cdot 3 \mathrm{H}_{2} \mathrm{O}$ & 0.476 \\
6 & $\mathrm{MgCl}_{2} \cdot \mathrm{H}_{2} \mathrm{O}$ & 0.622 \\
7 & $\mathrm{HEPES}$ & 23.856 \\
8 & $\mathrm{CaCl}_{2}$ & 0.586 \\
9 & $\mathrm{Na}_{2} \mathrm{SO}_{4}$ & 0.144 \\
10 & $1 \mathrm{M}-\mathrm{NaOH}$ & $3 \mathrm{~mL}$ \\
\hline
\end{tabular}

Commercially pure $\mathrm{Ti}$ plates were purchased from Goodfellow and cut to $1 \times 2.5 \mathrm{~cm}^{2}$. Platinum/Rhodium foil (Pt90/Rh10) of $25 \times 25 \times 0.125 \mathrm{~mm}^{3}$ size was purchased from Goodfellow and used as the cathode in the electropolishing unit.

\subsection{Electropolishing}

Before electropolishing, the as-received Ti substrates were first polished with a \#1000 and then a \#2400 silicon carbide grinding paper to remove the native oxide layer. The polished substrates were cleaned by sonication in distilled water, ethanol and then acetone, and finally dried in air.

The electrochemical cell was home-made (Figure 10a) and a mixture of $54 \mathrm{~mL}$ methanol, $25 \mathrm{~mL}$ 1-butanol and $6 \mathrm{ml}$ perchloric acid was used as the electrolyte. Electropolishing was conducted at $-30^{\circ} \mathrm{C}$, under an anodic potential of $9.5 \mathrm{~V}$ for $5 \mathrm{~min}$. Vigorous agitation was maintained throughout the process in order to obtain a homogenously electropolished surface [91]. Once electropolished, the Ti substrate was sonicated in methanol, ethanol and water, and finally dried under blowing Ar before storage under Ar (substrate denoted EP-Ti). The electropolished surface had a mirror finish as shown in Figure 10b. 
Figure 10. (a) Schematic of the home made electropolishing unit; (b) Photo of a substrate with the electropolished surface at half length. The reflection of the ruler on the electropolished part is clearly seen.
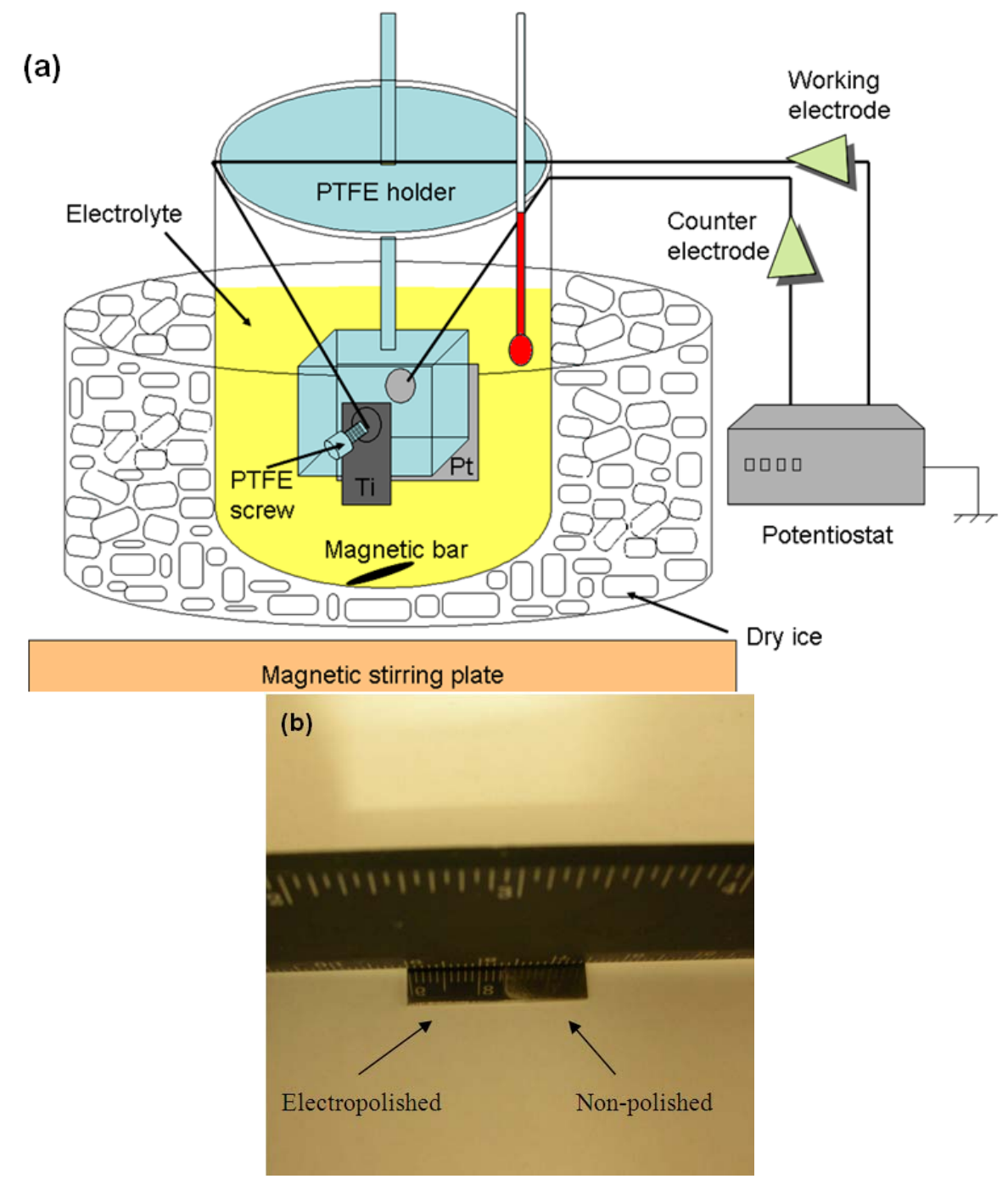

\subsection{Conventional Surface Treatments}

The as-received $\mathrm{Ti}$ substrates were cleaned by sonication in water, ethanol and acetone. Three conventional chemical treatments were used to modify the surface chemistry of the Ti substrates: (a) immersion in a 2:1 Piranha solution ( $v: v, \mathrm{H}_{2} \mathrm{SO}_{4}: \mathrm{H}_{2} \mathrm{O}_{2}$ ) at $100{ }^{\circ} \mathrm{C}$ for $10 \mathrm{~min}$ (substrate denoted Pi-Ti); (b) soaking in a $5 \mathrm{M}$ sodium hydroxide $(\mathrm{NaOH})$ solution at room temperature for $24 \mathrm{~h}$ (substrate denoted Na-Ti); (c) dipping in a mixture of $8.8 \mathrm{M} \mathrm{H}_{2} \mathrm{O}_{2}+0.1 \mathrm{M} \mathrm{HCl}$ at $80{ }^{\circ} \mathrm{C}$ for $1 \mathrm{~h}$ (substrate denoted Cl-Ti). All substrates were rinsed with a copious amount of distilled water after chemical treatments and then blow dried with Ar.

\subsection{CaP Coating}

For the nucleation and growth of HA, a "revised" SBF solution was used (see Table 3 for composition) [92]. In order to decrease the immersion time required to start the process of mineralization in SBF, a 1.5 SBF was used. Using 1.5 SBF, and not $1 \mathrm{SBF}$, is not conflicting with the 
report of Kokubo et al. [93], as the scope of the current study is not to evaluate the in vivo bone bioactivity of a material, and the SBF is used as a supersaturated solution with calcium and phosphate to study the effect of surface charge in the nucleation and growth of calcium phosphate phases in vitro. 1.5 SBF was prepared by dissolving the chemicals listed in Table 3 in sequence in 1,000 $\mathrm{mL}$ of high purity water in a polyethylene beaker at $36.5{ }^{\circ} \mathrm{C}$ under Ar. The solution was buffered at $\mathrm{pH}=7.4$ at $36.5{ }^{\circ} \mathrm{C}$ and the stock solution showed no precipitations after 1 month at $4{ }^{\circ} \mathrm{C}$. Three substrates per treatment group were prepared and suspended with a cotton thread individually in $20 \mathrm{~mL}$ of $1.5 \mathrm{SBF}$ at $36.5{ }^{\circ} \mathrm{C}$ in a polyethylene bottle under Ar to limit $\mathrm{CO}_{2}$ dissolution. The sealed bottles were stirred throughout the experiments and the solution was refreshed every 3 days. Once the substrates were removed from the solution, they were washed gently with high purity water and dried under flowing Ar. The substrates were stored under Ar until being characterized.

\subsection{Characterization Methods}

The chemical composition of $\mathrm{Ti}$ surfaces before $\mathrm{CaP}$ coating was determined by X-ray Photoelectron Spectroscopy (XPS) using a VG-Microtech Mutilab 3000 instrument. The XPS measurements were performed at $10^{-7} \mathrm{~Pa}$ with an $\mathrm{Al} \mathrm{K \alpha}$ source at $150 \mathrm{~W}$.

The surface morphology of $\mathrm{Ti}$ substrates before and after $\mathrm{CaP}$ coating was further characterized using a Field Emission Scanning Electron Microscope (FE-SEM) JEOL 6301 operated at $5 \mathrm{kV}$. Chemical composition of the surface with CaP coating was gained by Energy-dispersive X-ray (EDX) analysis. Further characterization of the chemical composition of the HA coating was done by Infrared spectroscopy. A Digilab Fourier Transform Infrared (FTIR) spectrophotometer equipped with a diffuse reflectance accessory was used. The spectra were collected with 100 scans at a resolution of $4 \mathrm{~cm}^{-1}$. The crystallographic structure of the $\mathrm{CaP}$ film was analyzed using a Bruker thin film X-ray Diffractometer (XRD) equipped with a $\mathrm{Cu} \mathrm{K \alpha}$ radiation source. The starting incident angle used was $5^{\circ}$.

\section{Conclusions}

The formation of bone-like apatite film was achieved on the surface of all chemically treated substrates despite differences in mechanism of HA growth and kinetics, with an enhancement of HA mineralization at negatively charged surfaces. Hence, the electropolished Ti surface was found to be capable of inducing bone-like apatite and the formation of an AB-type carbonated HA layer was confirmed after only a few days of immersion of the substrate in SBF. The enhanced HA induction ability of electropolished $\mathrm{Ti}$ is believed to result from residual surface $\mathrm{Cl}^{-}$formed during electrochemical process. By providing sites to the adsorption of $\mathrm{Ca}^{2+}$, such surface $\mathrm{Cl}^{-}$would facilitate the nucleation and growth of HA. Therefore, electropolishing of Ti surfaces could be an alternative route to chemical modification techniques for facilitated growth of apatite on $\mathrm{Ti}$ surfaces via biomimetic methods.

\section{Acknowledgments}

This work was supported by Furlong Research Foundation (and Joint Replacement Instrumentation (JRI) Orthopaedics Limited), UK. 


\section{References}

1. Liu, X.; Chu, P.K.; Ding, C. Surface modification of titanium, titanium alloys, and related materials for biomedical applications. Mater. Sci. Eng. A 2004, 47, 49-121.

2. Brunnette, D.M.; Tengvall, P.; Textor, M.; Thomsen, P. Titanium in Medicine. Materials Science, Surface Science, Engineering, Biological Responses and Medical Applications; Springer: Berlin, Germany, 2001.

3. Gross, K.A.; Berndt, C.C. Thermal processing of hydroxyapatite for coating production. J. Biomed. Mater. Res. 1998, 39, 580-587.

4. Steinemann, S.G. Titanium-The materials of choice? Periodontology 2000 1998, 17, 7-21.

5. Koutsopoulos, S. Kinetic study on the crystal growth of hydroxyapatite. Langmuir 2002, 17, 8092-8097.

6. Blackwood, D.J.; Seah, K.H.W. Galvanostatic pulse deposition of hydroxyapatite for adhesion to titanium for biomedical purposes. Mater. Sci. Eng. C 2010, 30, 561-565.

7. Ueda, M.; Ikeda, M.; Ogawa, M. Chemical-hydrothermal combined surface modification of titanium for improvement of osteointegration. Mater. Sci. Eng. C 2009, 29, 994-1000.

8. Sun, L.; Berndt, C.C.; Gross, K.A.; Kucuk, A. Material fundamentals and clinical performance of plasma-sprayed hydroxyapatite coatings: A review. J. Biomed. Mater. Res. 2001, 58, 570-592.

9. Habibovic, P.; Barrere, F.; van Blitterswijk, C.A.; de Groot, K.; Layrolle, P. Biomimetic hydroxyapatite coating on metal implants. J. Am. Ceram. Soc. 2002, 85, 517-522.

10. Stumm, W. Chemistry of the Solid-Water Interface: Processes at the Mineral-Water and Particle-Water Interface in Natural Systems; Wiley-Interscience: Weinheim, Germany, 1992.

11. Li, P.; Zhang, F. The electrochemistry of a glass surface and its application to bioactive glass in solution. J. Non Cryst. Solids. 1990, 119, 112-118.

12. Calvert, P.; Mann, S. The nagtive side of crystal growth. Nature 1997, 386, 127-128.

13. Wang, X.; Hayakawa, S.; Tsurub, K.; Osaka, A. Bioactive titania gel layers formed by chemical treatment of Ti substrate with a $\mathrm{H}_{2} \mathrm{O}_{2} / \mathrm{HCl}$ solution. Biomaterials 2002, 23, 1353-1357.

14. Lee, B.H.; Kim, Y.D.; Shin, J.H.; Lee, K.H. Surface modification by alkali and heat treatments in titanium alloys. J. Biomed. Mater. Res. 2002, 61, 466-473.

15. Kim, H.M.; Miyaji, F.; Kokubo, T.; Nakamura, T. Preparation of bioactive Ti and its alloys via simple chemical surface treatment. J. Biomed. Mater. Res. 1996, 32, 409-417.

16. Wei, M.; Kim, H.M.; Kokubo, T.; Evans, J.H. Optimising the bioactivity of alkaline-treated titanium alloy. Mater. Sci. Eng. C 2002, 20, 125-134.

17. Wen, H.B.; de Wijn, J.R.; Liu, Q.; de Groot, K. A simple method to prepare calcium phosphate coatings on Ti6Al4V. J. Mater. Sci. Mater. Med. 1997, 8, 765-770.

18. Pham, M.T.; Maitz, M.F.; Matz, W.; Reuther, H.; Richter, E.; Steiner, G. Promoted hydroxyapatite nucleation on titanium ion-implanted with sodium. Thin Solid Films 2000, 379, $50-56$.

19. Majewski, P.J.; Allidi, G. Synthesis of hydroxyapatite on titanium coated with organic self-assembled monolayers. Mater. Sci. Eng. A 2006, 420, 13-20.

20. Huang, S.; Zhou, K.; Liu, Y.; Huang, B. Controlled crystallization of hydroxyapatite under hexadecylamine self-assembled monolayer. Trans. Nonferrous Met. Soc. China 2003, 13, 595-599. 
21. Zhu, P.; Masuda, Y.; Koumoto, K. A novel approach to fabricate Hydroxyapatite coating on titanium substrate in an aqueous solution. J. Ceram. Soc. Jpn. 2001, 109, 676-680.

22. Tanahashi, M.; Matsuda, T. Surface functional group dependence on apatite formation on self-assembled monolayers in a simulated body fluid. J. Biomed. Mater. Res. 1997, 34, 305-315.

23. Li, P.; Ohtsuki, C.; Kokubo, T.; Nakanishi, K.; Soga, N.; de Groot, K. The role of hydrated silica, titania, and alumina in inducing apatite on implants. J. Biomed. Mater. Res. 1994, 28, 7-15.

24. Ajami, E.; Aquey-Zinsou, K.F. Formation of OTS self-assembled monolayers at chemically treated titanium surfaces. J. Mater. Sci. Mater. Med. 2011, 22, 1813-1824.

25. Zhu, P.; Masuda, Y.; Koumoto, K. The effect of surface charge on hydroxyapatite nucleation. Biomaterials 2004, 25, 3915-3921.

26. Hanawa, T.; Kamiura, Y.; Yamamoto, S.; Kohgo, T.; Amemiya, A.; Ukai, H.; Murakami, K.; Asaoka, K. Early bone formation around calcium-ion-implanted titanium inserted into rat tibia. J. Biomed. Mater. Res. 1997, 36, 131-136.

27. Xie, Y.; Liu, X.; Chu, P.K.; Ding, C. Nucleation and growth of calcium-phosphate on Ca-implanted titanium surface. Surf. Sci. 2006, 600, 651-656.

28. Wan, Y.Z.; Huang, Y.; He, F.; Wang, Y.L.; Zhao, Z.G.; Ding, H.F. Effect of Mg ion implantation on calcium phosphate formation on titanium. Surf. Coating Tech. 2006, 201, 2904-2909.

29. Maitz, M.F.; Pham, M.T.; Matz, W.; Reuther, H.; Steiner, G.; Richter, E. Ion beam treatment of titanium surfaces for enhancing deposition of hydroxyapatite from solution. Biomol. Eng. 2002, 19, 269-272.

30. Hanawa, T. In vivo metallic biomaterials and surface modification. Mater. Sci. Eng. A 1999, 267, 260-266.

31. Feng, B.; Chen, J.Y.; Qi, S.K.; He, L.; Zhao, J.Z.; Zhang, X.D. Carbonate apatite coating on titanium induced rapidly by precalcification. Biomaterials 2002, 23, 173-179.

32. Jobin, M.; Taborelli, M.; Descouts, P. Surface properties of electropolished titanium and vanadium. Appl. Surf. Sci. 1993, 72, 363-372.

33. Lausmaa, J.; Kasemo, B.; Mattsson, H.; Odelius, H. Multi-technique surface characterization of oxide films on electropolished and anodically oxidized titanium. Appl. Surf. Sci. 1990, 45, 189-200.

34. Mathieu, J.B.; Mathieu, H.J.; Landolt, D. Electropolishing of titanium in perchloric acid-Acetic acid solution. J. Electrochem. Soc. 1978, 125, 1039-1043.

35. Larsson, C.; Thomsen, P.; Lausmaa, J.; Rodahl, M.; Kasemo, B.; Ericson, L.E. Bone response to surface modified titanium implants: Studies on electropolished implants with different oxide thicknesses and morphology. Biomaterials 1994, 15, 1062-1074.

36. Meredith, D.O.; Eschbach, L.; Wood, M.A.; Riehle, M.O.; Curtis, A.S.G.; Richards, R.G. Human fibroblast reactions to standard and electropolished titanium and Ti-6Al-7Nb, and electropolished stainless steel. J. Biomed. Mater. Res. A 2005, 75, 541-555.

37. Lewandowska, M.; Wlodkowska, M.; Olkowski, R.; Roguska, A.; Polak, B.; Pisarek, M.; Lewandowska-Szumiel, M.; Kurzydłowski, K.J. Chemical surface modifications of titanium implants. Macromol. Symp. 2007, 253, 115-121.

38. Fatehi, k.; Moztarzadeh, F.; Solati-Hashjin, M.; Tahriri, M. In vitro biomimetic deposition of apatite on alkaline and heat treated Ti6Al4V alloy surface. Bull. Mater. Sci. 2008, 31, 101-108. 
39. Chen, Y.; Zheng, X.; Ji, H.; Ding, C. Effect of Ti-OH formation on bioactivity of vacuum plasma sprayed titanium coating after chemical treatment. Surf. Coating Tech. 2007, 202, 494-498.

40. Takadama, H.; Kim, H.M.; Kokubo, T.; Nakamura, T. XPS study of the process of apatite formation on bioactive Ti-6Al-4V alloy in simulated body fluid. Sci. Tech. Adv. Mater. 2001, 2, 389-396

41. Ntais, S.; Dracopoulos, V.; Siokou, A. $\mathrm{TiCl}_{4}(\mathrm{THF})_{2}$ impregnation on a flat $\mathrm{SiO}_{\mathrm{x}} / \mathrm{Si}\left(\begin{array}{lll}1 & 0 & 0\end{array}\right)$ and on polycrystalline $\mathrm{Au}$ foil: Determination of surface species using XPS. J. Mol. Catal. A Chem. 2004, 220, 199-205.

42. Lausmaa, J. Surface spectroscopic characterization of titanium implant materials. J. Electron Spectros. Relat. Phenom. 1996, 81, 343-361.

43. Feng, B.; Chen, J.Y.; QI, S.K.; He, L.; Zhao, J.Z.; Zhang, X.D. Characterization of surface oxide films on titanium and bioactivity. J. Mater. Sci. Mater. Med. 2002, 13, 457-464.

44. Takeuchi, M.; Abe, Y.; Yoshida, Y.; Nakayama, Y.; Okazaki, M.; Akagawa, Y. Acid pretreatment of titanium implants. Biomaterials 2003, 24, 1821-1827.

45. Pouilleau, J.; Devilliers, D.; Groult, H. Surface study of a titanium-based ceramic electrode material by X-ray photoelectron spectroscopy. J. Mater. Sci. Eng. A 1997, 32, 5645-5651.

46. Lu, G.; Bernasek, S.L.; Schwartz, J. Oxidation of a polycrystalline titanium surface by oxygen and water. Surf. Sci. 2000, 458, 80-90.

47. Shirkhanzadeh, M. XRD and XPS characterization of superplastic $\mathrm{TiO}_{2}$ coatings prepared on Ti6Al4V surgical alloy by an electrochemical method. J. Mater. Sci. Mater. Med. 1995, 6, 206-210.

48. Sundgren, J.E.; Bodo, P.; Lundstrom, I. Auger electron spectroscopic studies of the interface between human tissue and implants of titanium and stainless steel. J. Colloid Interface Sci. 1986, 110,9-20.

49. Sham, T.K.; Lazarus, M.S. X-ray photoelectron spectroscopy (XPS) studies of clean and hydrated $\mathrm{TiO}_{2}$ (Rutile) surfaces. Chem. Phys. Lett. 1979, 68, 426-432.

50. Boehm, H.P. Acidic and basic properties of hydroxylated metal oxide surfaces. Discuss. Faraday Soc. 1971, 52, 264-275.

51. Kokubo, T. Design of bioactive bone substitutes based on mineralization process. Mater. Sci. Eng. C 2005, 25, 97-104.

52. Resende, C.X.; Dille, J.; Platt, G.M.; Bastos, N.I.; Soares, G.A. Characterization of coating produced on titanium surface by a designed solution containing calcium and phosphate ions. Mater. Chem. Phys. 2008, 109, 429-435.

53. Kokubo, T.; Kim, H.M.; Kawashita, M.; Nakamura, T. Bioactive metals: Preparation and properties. J. Mater. Sci. Mater. Med. 2004, 15, 99-107.

54. Wang, X.X.; Hayakawa, S.; Tsuru, K.; Osaka, A. Improvement of bioactivity of $\mathrm{H}_{2} \mathrm{O}_{2} / \mathrm{TaCl}_{2}$-treated titanium after subsequent heat treatments. J. Biomed. Mater. Res. 2000, 52, 171-176.

55. Cui, X.; Kim, H.M.; Kawashita, M.; Wang, L.; Xiong, T.; Kokubo, T.; Nakamura, T. Effect of hot water and heat treatment on the apatite-forming ability of titania films formed on titanium metal via anodic oxidation in acetic acid solutions. J. Mater. Sci. Mater. Med. 2008, 19, 1767-1773. 
56. Takemoto, M.; Fujibayashi, S.; Neo, M.; Suzuki, J.; Matsushita, T.; Kokubo, T.; Nakamura, T. Osteoinductive porous titanium implants: Effect of sodium removal by dilute $\mathrm{HCl}$ treatment. Biomaterials 2006, 27, 2682-2691.

57. Barrere, F.; Snell, M.E.; van Blitterswijk, C.A.; De Groot, K.; Layrolle, P. Nano-scale study of the nucleation and growth of calcium phosphate coating on titanium implants. Biomaterials 2004, 25, 2901-2910.

58. Kokubo, T.; Kim, H.M.; Kawashita, M. Novel bioactive materials with different mechanical properties. Biomaterials 2003, 24, 2161-2175.

59. Uchida, M.; Kim, H.M.; Fujibayashi, S.; Nakamura, T. Structural dependence of apatite formation on titania gels in a simulated body fluid. J. Biomed. Mater. Res. 2003, 64A, 164-170.

60. Bigi, A.; Boanini, E.; B. Bracci; A. Facchini; S. Panzavolta; F. Segatti; L. Sturba nanocrystalline hydroxyapatite coatings on titanium:a new fast biomimetic method. Biomaterials 2005, 26, 4085-4089.

61. Uchida, M.; Kim, H.M.; Kokubo, T.; Fujibayashi, S.; Nakamura, T. Effect of water treatment on the apatite-forming ability of $\mathrm{NaOH}$-treated titanium metal. J. Biomed. Mater. Res. 2002, 63, $522-530$.

62. Li, F.; Feng, Q.L.; Cui, F.Z.; Li, H.D.; Schubert, H. A simple biomimetic method for calcium phosphate coating. Surf. Coating Tech. 2002, 154, 88-93.

63. Davies, J.E. Bone bonding at natural and biomaterial surfaces. Biomaterials 2007, 28, 5058-5067.

64. Davies, J.E. Understanding peri-implant endosseous healing. J. Dent. Educ. 2003, 67, 932-949.

65. You, C.; OH, S.; Kim, S. Influences of heating condition and substrate-surface roughness on the characteristics of sol-gel-derived hydroxyapatite coatings. J. Sol-Gel Sci. Tech. 2001, 21, 49-54.

66. Blackwood, D.J.; Seah, K.H. Seah Influence of anodization on the adhesion of calcium and phosphate coatings on titanium substrates. J. Biomed. Mater. Res. 2009, 93A, 1551-1556.

67. Liu, D.P.; Majewski, P.J.; O'Neill, B.K.; Ngothai, Y.; Colby, C.B. The optimal SAM surface functional group for producing a biomimetic HA coating on Ti. J. Biomed. Mater. Res. 2006, 77A, $763-772$.

68. Lin, C.M.; Yen, S.K. Characterization and bond strength of electrolytic $\mathrm{HA} / \mathrm{TiO}$ double layers for orthopaedic applications. J. Mater. Sci. Mater. Med. 2005, 16, 889-897.

69. Koutsopoulos, S. Synthesis and characterization of hydroxyapatite crystals: A review study on the analytical methods. J. Biomed. Mater. Res. 2002, 62, 600-612.

70. Li, H.; Huang, W.; Zhang, Y.; Zhong, M. Biomimetic synthesis of enamel-like hydroxyapatite on self-assembled monolayers. Mater. Sci. Eng. C 2007, 27, 756-761.

71. Yousefpour, M.; Afashar, A.; Yang, X.; Li, X.; Yang, B.; Wu, Y.; Chen, J.; Zhang, X. Nano-crystalline growth of electrochemically deposited apatite coating on pure titanium. J. Electroanal. Chem. 2006, 589, 96-105.

72. Leeuwenburgh, S.; Layrolle, P.; Barrere, F.; de Bruijn, J.; Schoonman, J.; van Blitterswijk, C.A.; de Groot, K. Osteoclastic resorption of biomimetic calcium phosphate coatings in vitro. J. Biomed. Mater. Res. 2001, 56, 208-215.

73. He, L.; Feng, Z. Preparation and characterization of dicalcium phosphate dihydrate coating on enamel. Mater. Lett. 2007, 61, 3923-3926. 
74. Ermrich, M.; Peters, F. X-ray powder diffraction data of synthetic b-tricalcium phosphate. Z. Kristallogr. Suppl. 2006, 23, 523-528.

75. Furuzono, T.; Walsh, D.; Yasuda, S.; Sato, K.; Tanaka, J.; Kishida, A. Preparation of plated $\beta$-tricalcium phosphate containing hydroxyapatite for use in bonded inorganic-organic composites. J. Mater. Sci. 2005, 40, 2595-2597.

76. Rajabi-Zamani, A.H.; Behnamghader, A.; Kazemzadeh, A. Synthesis of nanocrystalline carbonated hydroxyapatite powder via nonalkoxide sol-gel method. Mater. Sci. Eng. C 2008, 28, $1326-1329$.

77. Kim, H.E.; Himeno, T.; Kawashita, M.; Kokubo, T.; Nakamura, T. The mechanism of biomineralization of bone-like apatite on synthetic hydroxyapatite: An in vitro assessment. J. R. Soc. Interface 2004, 1, 17-22.

78. Kim, H.M.; Miyaji, F.; Kokubo, T. Effect of heat treatment on apatite-forming ability of Ti metal induced by alkali treatment. J. Mater. Sci. Mater. Med. 1997, 8, 341-347.

79. Schmidt, M. X-ray photoelectron spectroscopy studies on adsorption of amino acids from aqueous solutions onto oxidised titanium surfaces. Arch. Orthop. Trauma Surg. 2001, 121, 403-410.

80. Tomazic, B.; Tomson, M.; Nancollas, G.H. Growth of calcium phosphates on hydroxyapatite crystals: The effect of magnesium. Arch. Oral. Biol. 1975, 20, 803-808.

81. Barrere, F.; van Blitterswijk, C.A.; de Groot, K.; Layrolle, P. Nucleation of biomimetic Ca-P coatings on Ti6A14V from a SBF $\times 5$ solution: influence of magnesium. Biomaterials 2002, 23, 2211-2220.

82. Salimi, M.H.; Heughebaert, J.C.; Nancollas, G.H. Crystal growth of calcium phosphates in the presence of magnesium ions. Langmuir 1985, 1, 119-122.

83. Rey, C.; Bracci, B.; Goehl, T.; Dickson, I.R.; Glimcher, M.J. The carbonate environment in bone mineral: A resolution-enhanced fourier transform infrared spectroscopy study. Calcif. Tissue Int. 1989, 45, 157-164.

84. Vignoles, M.; Bonel, G.; Holcomb, D.W.; Young, R.A. Influence of preparation conditions on the composition of type B carbonated hydroxyapatite and on the localization of the carbonate ions. Calcif. Tissue Int. 1988, 43, 33-40.

85. Cheng, Z.H.; Yasukawa, A.; Kandori, K.; Ishikawa, T. FTIR study on incorporation of $\mathrm{CO}_{2}$ into calcium hydroxyapatite. J. Chem. Soc. Faraday Trans. 1998, 94, 1501-1505.

86. Zhang, Q.; Chen, J.; Feng, J.; Cao, Y.; Deng, C.; Zhang, X. Dissolution and mineralization behaviours of HA coatings. Biomaterials 2003, 24, 4741-4748.

87. Chang, M.C.; Douglas, W.H.; Tanaka, J. Organic-inorganic interaction and the growth mechanism of hydroxyapatite crystals in gelatin matrices between 37 and $80{ }^{\circ}$ C. J. Mater. Sci. Mater. Med. 2006, 17, 387-396.

88. Stoch, A.; Jastrzebski, W.; Brozek, A.; Trybalska, B.; Cichocinska, M.; Szarawara, E. FTIR monitoring of the growth of the carbonate containing apatite layers from simulated and natural body fluids. J. Mol. Struct. 1999, 511-512, 287-294.

89. Muller, L.; Conforto, E.; Caillard, D.; Muller, F.A. Biomimetic apatite coatings-Carbonate substitution and preferred growth orientation. Biomol. Eng. 2007, 24, 462-466.

90. Landi, E.; Tampieri, A.; Celotti, G.; Vichi, L.; Sandri, M. Influence of synthesis and sintering parameters on the characteristics of carbonate apatite. Biomaterials 2004, 25, 1763-1770. 
91. Piotrowski, O.; Madore, C.; Landolt, D. The mechanism of electropolishing of titanium in methanol-sulfuric acid electrolytes. J. Electrochem. Soc. 1998, 145, 2362-2369.

92. Kim, H.M.; Miyazaki, T.; Kokubo, T.; Nakamura, T. Revised simulated body fluid. Key Eng. Mater. 2001, 192-195, 47-50.

93. Kokubo, T.; Takadama, H. How useful is SBF in predicting in vivo bone bioactivity? Biomaterials 2006, 27, 2907-2915.

(C) 2012 by the authors; licensee MDPI, Basel, Switzerland. This article is an open access article distributed under the terms and conditions of the Creative Commons Attribution license (http://creativecommons.org/licenses/by/3.0/). 